\title{
Spiritualiteit en armenzorg bij Six van Chandelier, Cats en Lodensteyn
}

\section{A. SCHENKEVELD-VAN DER DUSSEN}

Een literatuur-historicus is op een congres van 'gewone historici' een wat vreemde eend in de bijt. Hoewel de beoefenaars van de literatuurgeschiedenis ervan doordrongen zijn dat er zeker in de zeventiende eeuw een nauw verband bestaat tussen literatuur en samenleving, literatuur en politiek, literatuur en religie, is het hun opdracht toch met nadruk op de eigenheid van de literatuur te wijzen. Vanuit dat perspectief is het wat problematisch een beschouwing te moeten leveren over de vraag hoe het met de godsdienstige beleving in de Republiek gesteld is, via de toegangsweg van de literatuur. Dat is eigenlijk geen literaire vraagstelling. Men kan zich zelfs meer in het algemeen afvragen of het een verstandige vraagstelling is. Het is immers wel mogelijk te spreken over 'de Franciscaanse spiritualiteit' of over 'de gereformeerde zede', maar op die wijze is de literatuur geen eenheid. Men kan niet spreken over 'literaire zedelijkheid' of 'dichterlijke geloofsbeleving',hoeveel dichters er ook, zoals dat in de zeventiende eeuw het geval was, aan de religie ruimte hebben gegeven in hun dichtbundels. Zoveel hoofden, zoveel zinnen blijft het parool. Zelfs binnen het werk van één dichter kunnen zich ingrijpende verschillen voordoen. Marijke Spies heeft bijvoorbeeld aan de hand van Vondels zeevaart-gedichten laten zien hoe anders de doopsgezinde Vondel denkt en voelt dan de remonstrantse ${ }^{1}$. Onder het ene (dwaze) hoofdje 'literaire ethiek' zou ik u kunnen presenteren Matthijs van de Merwede van Clootwijck met zijn principieel beroep op de natuur om zijn erotisch-libertijnse gedrag te verdedigen en de rondzwervende ex-predikant Dirck Rafaelsz. Camphuysen die onvermoeibaar de volmaakte deugd predikt ${ }^{2}$. Zo gezien heeft een literatuur-historicus, althans voorzover die zich bij zijn leest wil houden, u niet zo veel te bieden. Literaire bronnen zijn vanuit de 'gewone' historische vraagstellingen niet van andere aard dan brieven, pamfletten of preken en dichters melden, vanuit uw perspectief, niets anders dan andere burgers. Maar wij literatuur-historici behoren die teksten als literatuur te lezen en letten dan in de eerste plaats op literaire aspecten: poëtica, stijlniveau, versvorm, genre, plaats in de literaire traditie en in het literaire bedrijf. En als we tenslotte ook graag en vaak aandacht geven aan de functie van de literatuur in de samenleving — want dat behoort niet minder tot onze opdracht—en ons dus om onze teksten te plaatsen in het buurland van de historici begeven, dan gebruiken we de methoden, technieken en resultaten van de politieke, kerk- of cultuurgeschiedenis, het zij met eerbied gezegd, als hulpwetenschap. En andersom doet u hetzelfde.

Om u terwille te zijn concentreer ik me vandaag dus op dichters die niet vanuit hun

1 J. van den Vondel, Twee zee-vaartgedichten (2 dln.; Amsterdam-Oxford-New York, 1987) I, 31-65. 2 Vgl. M. A. Schenkeveld-van der Dussen, 'De poëtica van een libertijnse zelf-voyeur', De nieuwe taalgids, LXXXII ( 1989) 2-15 en Idem, 'Camphuysen en het genus humile' in: Eer is het lof des deughts. Opstellen over renaissance en classicisme aangeboden aan dr. Fokke Veenstra (Amsterdam, 1986) 141 153. 
poeticale opvattingen maar vanuit hun geestelijke achtergrond met elkaar te vergelijken zijn - en dat betekent in zekere zin dat hun dichterschap er dan minder toe doet dan hun geestelijke ligging als burgers van de Republiek — drie goed-gereformeerde broeders. Dan nog zal trouwens blijken dat bij alles wat hen verbindt, er toch ook veel is dat hen onderscheidt op het gebied van geloofsbeleving en praxis pietatis. Wat dat laatste betreft, heb ik een deelonderwerp gekozen om de drie te kunnen vergelijken: het omgaan met het eigen aardse goed en de diaconale zorg. Twee van de drie gekozenen, Jacob Cats en Jodocus van Lodensteyn, hebben een grote groep lezers gevonden blijkens de vele herdrukken van hun werk die verschenen zijn. Van het werk van de derde, Jan Six van Chandelier, heeft tot verleden jaar nooit een herdruk het licht gezien en toch is het vermoeden niet ongerechtvaardigd dat hij in leer en leven misschien wel het meest de doorsnee-gereformeerde vertegenwoordigt, hoezeer hij in zijn kwaliteit als dichter ook uitmiddelpuntig was. Ook dat laat even zien hoe ingewikkeld de zaken liggen.

Jan Six van Chandelier ( 1620-1695) was een gefortuneerd koopman in geneeskrachtige kruiden te Amsterdam, die voor zijn handelsonderneming enkele reizen in ZuidEuropa en Engeland heeft gemaakt. De studie van zijn werk, dat bestaat uit de bundel Pö̈zy van 1657, wat losse gedichten en een psalmberijming, is aanzienlijk vergemakkelijkt omdat we sinds 1991 over een monumentale tekstuitgave beschikken van zijn gedichten (exclusief de psalmvertaling) ${ }^{3}$. Het tekstdeel telt een kleine 900, het commentaardeel bijna 1000 pagina's. Uit dat laatste valt op te maken dat Six van Chandelier een moeilijk dichter is, en wel vanwege zijn taalrijkdom, zijn gezochte duisterheid en zijn eruditie. Vandaar dat hij nooit populair is geworden. Anderzijds staat hij met zijn poëzie midden in het leven, en kiest hij gebeurtenissen, soms heel persoonlijke, uit het dagelijks leven van zichzelf en zijn tijdgenoten graag als onderwerp voor zijn gedichten.

Van Six' leven is enerzijds weinig bekend maar anderzijds weten we wat hem persoonlijk betreft buitengewoon veel omdat hij dat allemaal in zijn poëzie heeft neergelegd ${ }^{4}$. Zo is het ook met zijn leven als christen en kerkmens. Tal van details daarvan heeft hij ons in zijn gedichten beschreven. Op basis daarvan wil ik nu eerst kort zijn spiritualiteit kenschetsen.

In de eerste plaats is dan van belang het complex gedachten en gevoelens dat zich laat vangen in woorden als berusting, geborgenheid, Godsvertrouwen, geloof in Gods directe bemoeienis met deze wereld. Soms is dat, zoals zo vaak in deze periode, stoïsch gekleurd. Lijdzaamheid, patientia is de beste medicijn tegen lijden. Klagen en schreien helpt niet, zo voegt hij een dierbare vriendin toe bij het overlijden van haar man ${ }^{5}$. Wanneer hij op een van zijn reizen zich op een gegeven moment totaal vervreemd en onzeker voelt, zinloos van de ene plaats naar de andere dolend, vraagt hij zich eerst in

3 J. Six van Chandelier, Gedichten, A. E. Jacobs, ed. (2 dln.; Assen-Maastricht, 1991).

4 De belangrijkste biografica in Ibidem, II, xxxv-xl.

5 Ibidem, I, 235. 
de stoïsche terminologie af: 'Waar zal de slinger van 't vast noodgeheim my dryven?' maar aan het slot van het sonnet weet hij beter: ' $t$ Geheim was God. O God 'k beveel my in uw handen' ${ }^{6}$. Een vergelijkbaar wat berustend getoonzet Godsvertrouwen klinkt ook door in enkele gedichten naar aanleiding van de pest die in 1654-1655 te Amsterdam woedde. Zoals bekend bestond daaromtrent in de gereformeerde gezindte verschil van mening. Sommigen meenden dat men zich lijdzaam aan Gods straffende hand moest onderwerpen, anderen, waaronder Six' vriend en familielid Johannes Hoornbeeck, hoogleraar godgeleerdheid in Utrecht en behorend tot de kring der Nadere Reformatie, achtten het rechtmatig zich tegen de pest te verzetten, als de gezindheid vanwaaruit men dat doet maar juist is ${ }^{7}$. Bij Six is de vraagstelling omgedraaid: hij moet op zakenreis, toevalligerwijs in pesttijd, en een van zijn zusters heeft hem kennelijk gevraagd waarom hij hen, zijn moeder, broers en zusters, nu alleen laat. Zijn antwoord is dat hij dat niet doet om Gods hand te ontgaan: die kan de zondaar nergens ontlopen. En ach, voegt hij eraan toe, mocht ik maar sterven en rust verwerven. Andersom, zijn aan- of afwezigheid doet niet terzake. Als God wil kan Hij, in heel het pestig Amsterdam, juist hun huis beschermen. En als God het anders wil, en verlies ik mijn familie, dan ben ik daaraan niet schuldig. Gods beschikking staat vast, daaraan kan de mens niets veranderen. Daarom ga ik mijn werk doen, met de beste bedoelingen. 'God spaar ons dak, voor ongemak, \en pest', zo beëindigt hij zijn gedicht met een gebed $^{8}$.

Op die manier krijgen God en mens elk hun eigen verantwoordelijkheden toegewezen. De mens moet, zo verstandig mogelijk, zijn taken verrichten, en in die zin is van lijdzaamheid geen sprake. Maar anderzijds weet hij zich geborgen in het grote plan Gods.

Bijna symbolisch uit zich dat in het gedicht waarin hij, alweer op reis, beschrijft hoe hij door Frankrijk trekt. We zien dan in een scherp vignet de calvinistische koopmandichter in optima forma. De menselijke verantwoordelijkheid wordt gesymboliseerd door de twee pistolen die hij in de zijtas draagt, het dichterschap door de bundel oden van Horatius, en het christen-zijn door het psalmboek:

Terwyl myn loome ruin Britanje gingh ontwyken

En Nantes, naa myn rugh, Rochelwaarts om liet kyken,

Droegh ik, in elke tasch, van twee gelaân pistoolen,

Hier Davids gulden harp, daar Flakkus lier verhoolen.

$\mathrm{Nu}$ om myn ziel, met sangh, ten Heemel, uit te storten,

En, met een heilge vreuchd, de lange wegh te korten:

Dan om het eensaem vleisch ook somwyl te vermaaken,

In styl van poesy, en werreldwyse saaken?

6 'Op myne doolreise tusschen Port S. Marye, en Granade', Ibidem, I, 59.

7 Vgl. L. Noordegraaf, G. Valk, De gave Gods. De pest in Holland vanaf de late middeleeuwen (Bergen, 1988) en de recensie van P. van Rooden in NRC-Handelsblad van 7 januari 1989.

8 'Op myne reise, naa Londen, aan myne suster, Katarina', Six van Chandelier, Gedichten, 1,735-736.

9 'Brief, aan Joannes Hoornbeek, te Uitrecht', Ibidem, I, 395. 
Als hij op reis in een diep gepeins is geraakt, wordt hij door de kwinkelerende vogels opgewekt om 'een orgellied uit dien godsaalgen schryver', David, te zingen. We hebben hier dus te maken met een christen die moeiteloos vanuit aardse beslommeringen het oog op de hemel gevestigd houdt.

Dat werkt ook andersom. De mens kan door zijn zonden de straffende hand Gods over zich afroepen. Six ziet, net als velen van zijn tijdgenoten overigens, tegenslagen, oorlogen, ziekten, ja zelfs het slechte weer, als pijnlijke maar heilzame tuchtmaatregelen des Heren die tot bekering moeten leiden ${ }^{10}$. In 1655 brengt hij een periode door in Spa om bij de bronnen aldaar genezing te zoeken voor een ernstige miltziekte. Op de wijze van de boetpsalm 6 vertolkt hij op een bevindelijke wijze de gevoelens van de vele aanwezige zieken. Genees ons, verlos ons van onze hevige pijnen, maar:

Dat wy zulk heil genieten

Zoo drenk ons eerst met vlieten

Uit Iesus bloedfontein.

Heilt ons van boose sonden

Oorsaken aller wonden,

Zoo werden wy gansch rein ${ }^{11}$.

Een tweede belangrijk element van zijn spiritualiteit is het complex dat te maken heeft met afkeer van hovaardij, schone schijn, pretenties. Voor Six' poëzie is dat van centrale betekenis en vanuit dat perspectief is er dan ook al het een en ander over geschreven ${ }^{12}$. Maar dat hij bewust aan zijn beoefening van de schone letteren geen buitengewoon belang wil hechten, en dat hij in het algemeen hoogst wantrouwend staat tegen de pretenties van dichters en dichtkunst, vloeit voort uit dat algemene gevoel voor de betrekkelijkheid van al het aardse. Dat weerhoudt hem er niet van, zoals inmiddels wel duidelijk zal zijn, zich er met volle teugen mee bezig te houden, zoals hij ook, met al zijn reserves tegenover de literatuur, een dik boek vol doorwerkte en herwerkte gedichten heeft geschreven. Maar dat gebeurt dan toch steeds met in het achterhoofd de gedachte dat het hier niet om zaken van het allerhoogste belang gaat. Daarvoor geldt het sursum corda. Hij heeft overtuigend in deze spanning geleefd. Er zijn weinig dichters in Nederland, en trouwens ook daarbuiten, die met zoveel overtuiging de aarde en alles wat daarop te beleven is, trouw zijn geweest. Voor de dichter Six van Chandelier is de hele wereld, zijn àl zijn ervaringen, van de verhevenste tot de banaalste, bruikbaar materiaal. En anderzijds moeten ook al die aardse waarden en ervaringen gerelativeerd worden. In verband daarmee wijs ik op de opbouw van zijn bundel als geheel. Die is namelijk buitengewoon onoverzichtelijk. De reeks sonnetten waarmee het boek begint, heeft waarschijnlijk een chronologische ordening, maar in

10 Vgl. M. A. Schenkeveld-van der Dussen, 'Regen in het vredejaar' in: K. Porteman, K. E. Schöndorf, ed., Liber amicorum Kare Langvik-Johannessen (Leuven, 1989) 159-166.

11 'Spasangh. Op de wyse vanden 6.psalm', Six van Chandelier, Gedichten, I, 184.

12 M. A. Schenkeveld-van der Dussen, 'De anti-idealistische poetica van en christen-burger, Joannes Six van Chandelier', De nieuwe taalgids, LXXVI (1983) 291-316. 
de drie afdelingen 'Dichtbosch' lijkt volkomen willekeur te heersen. Six heeft kennelijk ook in poeticis een 'bosje', een silva, willen nabootsen, waarin bomen, planten, struiken en bloemen dooreen $\operatorname{staan}^{13}$. En zo vinden we bijvoorbeeld achter elkaar 'Afkeer van Isabelle' (een gedicht tegen een arrogant meisje), 'Op het H. Nachtmaal' en een satirisch gedicht 'Vrouwenmacht' (185-187); of, een ander voorbeeld: 'Oesters te Kolchester' waar heerlijk in gesmuld wordt, staat naast 'De vreese des Heeren, het begin der wy sheit ' (765-767). Een dergelijke ordening kan men al als een statement, ook op het gebied van de spiritualiteit beschouwen. Zij lijkt mij in dit geval in hoge mate gereformeerd toe. De ware calvinist ziet heel het leven onder de bestiering Gods en principieel gezien is er geen reden voor hem het leven in vakjes op te delen. In zeventiende-eeuwse bundels is een dergelijke bonte ordening uitzonderlijk. Normaal gesproken zijn bundels naar genre of naar onderwerp ingedeeld en 'geestelijke gedichten' vindt men dan ook meestal als een groep bijeengeplaatst.

Maar Six zet vele levensterreinen eenvoudig en naar mijn vaste overtuiging opzettelijk naast elkaar de liefde, de politiek, ziekte, geloofservaring en lekker eten — dat laatste komt betrekkelijk vaak voor: Six kan meeslepend schrijven over meloenen, schaapsbouten, zalmen of de beste kwaliteit oesters. Uit het rijtje kan worden opgemaakt dat van wereldmijding nauwelijks sprake is. Deze dichter geniet volop van het goede der aarde. Hij zou zich daarbij op Calvijn hebben kunnen beroepen, al vertoont het denken van de hervormer ook op dit punt de recent door Bouwsma naar voren gebrachte innerlijke tegenstrijdigheden ${ }^{14}$. In dit kader is het bijvoorbeeld interessant te lezen hoe Calvijn met de christelijke vrijheid omspringt in boek III van zijn Institutie ${ }^{15}$. In paragraaf 7 en 8 bepleit hij nadrukkelijk de vrijheid van de christen om 'de uiterlijke dingen, die op zichzelf middelmatig zijn' naar believen te gebruiken, als men er maar niet aan gebonden is. En vervolgens analyseert hij op een indringende manier de psychologie van degene die steeds minder mag van zichzelf. Als iemand

weifelt, of hij een goed merk wijn mag drinken, zal hij daarna ook geen slechte wijn met goeden vrede zijner consciëntie drinken; ten slotte zal hij ook geen water, dat lekkerderen zuiverder is dan ander water, durven aanraken (III, 9).

Alle uiterlijke dingen zijn aan onze vrijheid onderworpen, als maar onze gemoederen voor God van die vrijheid verzekerd zijn. En in X, 2 werkt hij dit nog verder uit door erop te wijzen dat God niet alleen 'voor den nooddruft, maar ook voor genieting en blijdschap heeft willen zorgen'.

In die zin is Six een goed calvinist. Hij leeft niet in hokjes, dicht over alles wat hem bezig houdt, heilig en profaan, en geniet van wat God te genieten geeft. In catechisatie en kerkdienst heeft hij de geloofswaarheden van zijn kerk ingeprent gekregen. Hij is erin geïnteresseerd en leeft ermee zondereen professionele theoloog te zijn. Zo kan hij,

13 Voor de overigens al uit de klassieke traditie stammende silva-opbouw: Ibidem, 291.

14 W. J. Bouwsma, John Calvin. A sixteenth century portrait (New York-Oxford, 1988).

15 Johannes Calvijn, Institutie of onderwijzing in de christelijke godsdienst. Uit het Latijn vertaald door A. Sizoo (3 dln.; Delft, 1956). 
voor wie strikt toekijkt, mogelijk wel eens dogmatisch in de fout gaan als hij bijvoorbeeld op een vreemde manier bezig is een Horatiaans deugdbegrip te koppelen aan een gereformeerd sola fide sola gratia ${ }^{16}$. Dat is dan echter juist het gevolg van zijn neiging al zijn denken en ervaren te confronteren met zijn christen-zijn. Ook zijn levensgenieten gebeurt dus niet naïef en kritiekloos maar sub specie aeternitatis. Hij relativeert de aardse geneugten, niet als een vervelende spelbederver, maar omdat hij bij alles wat hij met zoveel plezier doet, weet van de vergankelijkheid van het aardse. En zo worden er veel vraagtekens geplaatst: bij de eigen gezondheid, de eigen dichtersijdelheid, de pracht van de Spaanse koning, of de voorgenomen bouw van een toren bij de Nieuwe Kerk te Amsterdam ${ }^{17}$.

Toch kan men zich afvragen of Calvijn deze Amsterdamse koopman nu werkelijk als een voorbeeld van de juiste gereformeerde levenshouding zou hebben beschouwd. De hervormer liet op de zojuist gepostuleerde vrijheid van de christenmens ook onmiddellijk waarschuwingen volgen die de aangeboden vrijheid in feite toch wel sterk beperken en de christen, nolens volens, toch weer tot het zojuist afgewezen gepieker dreigen te brengen. Genieten mag, maar niet te veel en dan wordt er toch weer de staf gebroken over het aanrichten van maaltijden, de opsmuk van het lichaam en het bouwen van huizen omdat men daarbij dan toch weer vermaak schept in schittering en weelde (III, 9). Calvijn balanceert uiterst moeizaam, zoals ook blijkt uit een formulering als de volgende (III, 3) 'De gelovigen moeten zich gewennen aan zulk een verachting van dit leven, dat die [toch] geen haat tegen dat leven wekt en geen ondankbaarheid jegens God'. Die grens tussen wel verachten en niet haten mag wel flinterdun heten.

$\mathrm{Nu}$ is dit alles niet alleen of zelfs uitsluitend met levensovertuiging, laat staan dogmatiek, te verklaren. Ook de persoonlijkheid speelt een rol. De levensgenieter Six kiest voor een royaal gebruik van de hem toegestane christelijke vrijheid. Die medaille heeft ook haar keerzijde. Misschien is het geen toeval dat we in zijn poëzie die toch werkelijk over alles en nog wat gaat, ook lege plekken vinden. De diaconale zorg voor de medemens stond in de gereformeerde kerk hoog aangeschreven. Mededeelzaamheid was een van de manieren waarop de christen zijn dankbaarheid voor Gods genade kon tonen. Ook daarover geeft Calvijn aanwijzingen (III, 15). Over dat aspect van de praxis pietatis horen we echter bij Six niet al te veel. Hij prijst zijn vader om diens diakenschap en zijn royaliteit tegenover de armen, hij dicht een epigram op het nieuwe gebouw van de diaconie waarin hij de gulle gevers belooft dat ze niet 5 of $6 \%$ zullen opstrijken voor hun geld maar 'de hemel zelf in hun tas 'zullen krijgen. Ook wordt nog een zekere De Vik geprezen omdat hij bij zijn leven al veel weggaf en ook bij testament de armen goed bedacht ${ }^{18}$. Dat laatste voorbeeld heeft de dichter in elk geval niet

16 'Rykdom des gemoeds' in Six van Chandelier, Gedichten, I, 210.

17 Resp. 'Schyn bedriegt', Ibidem, I, 420, 'Ydel ooghmerk van boekschryven', Ibidem, I, 599; 'Hoe nietich dat de pracht der kooningen zy', Ibidem, I, 37 en 'Toorenbouw, aan de graavers', Ibidem, I, 212. 18 Resp. 'Grafdicht, op myn vaader', Ibidem, 1,239; 'Grafschrift', Ibidem, 1,492en 'Voor de diakonye', Ibidem, 1,553. 
gevolgd. In zijn testament is $f 1.200$,- voor de armen gereserveerd, een bedrag dat maar een heel klein deel vormt van het kapitaal dat hij aan zijn zuster naliet, 's Dichters zelfironie heeft trouwens juist ook op dit punt betrekking. Als hij op reis in Frankrijk gewekt wordt door het onwelluidend gefiedel van een troepje bedelaars scheept hij ze af met wat klein geld, ja zelfs waardeloze muntjes, waarna hij in het gedicht dat de anekdote vertelt met plechtige zelfspot sententieus eindigt: 'Wie 's morgens armen troost begint met heilig werk ${ }^{19}$. Hij weet kennelijk wel dat dit zijn sterkste kant niet is.

Ik wil naast hem nu eerst Jacob Cats (1 577-1660) leggen, de veelgelezen didacticus. Als ik Cats' spiritualiteit met één woord zou moeten kenschetsen, zou dat 'onrust' zijn. Zijn leven staat onder grote spanningen.

Enerzijds heeft het aardse leven zijn volle en niet aflatende aandacht: huiselijk leven, diergedrag, verhalen uit de hele wereld, volkswijsheid in spreekwoorden, hij is overal in geïnteresseerd en van alles heeft hij stof voor zijn poëzie weten te maken. Maar die belangstelling voor het volle aardse leven wordt in zoverre ook gecorrigeerd doordat alles verwijst naar het hogere, een aspect dat bij Six nu juist vrijwel ontbreekt. De wereld is één groot leerboek en de meest merkwaardige verbanden kunnen worden gelegd. Zo dicht hij 'Op 't gesichte van een vrouwe die met beulingen te sieden besig was'. Ze prikt in de worsten als die te bobbelig worden.

Mij hart bewoog tot in den grond

Soo haest ick dit bericht verstont.

O Heer! gy doet 'et menigmael

Dat my hier onder d'oogen valt,

Wanneer mijn weelig herte malt;

Ick hebbet vry al veel geproeft

Dat gy myn zinnen hebt bedroeft,

Dat gy (wanneer het dertel vleys,

$\mathrm{Nu}$ scheen te krijgen sijnen eys,

En dat mijn los en swinig vel

$\mathrm{Nu}$ was genegen tot geswel)

Dat gy dan in de bobbels staeckt,

En soo myn quade driften braeckt ${ }^{20}$.

Cats is een tobber. Steeds moet hij zichzelf (en daarmee de lezer) trachten gerust te stellen. Enerzijds is hij geboeid door het aardse, hij observeert het, hij geniet ervan. Hij heeft het ook goed, de gefortuneerde grootgrondbezitter. Anderzijds wantrouwt hij het aardse zeer: op alle gebieden waar geluk en voorspoed zich vertonen, dient men op gevaar bedacht te zijn. Onze gehechtheid aan het aardse betekent gevaar. De dood dreigt alom en neemt ons alles af. Het ware heil ligt elders en daarop moeten we ons

19 'Beedelmusyk, te Tholouse', Ibidem, I, 408.

20 Jacob Cats, Alle de wercken (2 dln.; Amsterdam, 1712) II, 398-399. 
voorbereiden door ons te onthechten. Zo bekeken zou de dood als bevrijding te beschouwen zijn. Dat is de theorie. Maar de praktijk is anders. Telkens kwelt hem de vrees voor de dood en dan toch vooral ook omdat die hem al het aardse goed zal afnemen.

Diezelfde onrust kwelt hem ook tegenover God. Net als Six is hij er vast van overtuigd dat Die zich tot in de kleinste details met het aardse leven bezighoudt. God toont ons zijn vaderlijke zorg, overal en altijd. Maar ook hier treffen we weer die onrust. God is voor Cats moeilijk te interpreteren, of misschien kan men wel zeggen: ook God benadert hij wantrouwend. Voorspoed: is dat niet gevaarlijk? In feite voelt hij zich veiliger bij tegenspoed: dat is te duiden als de tuchtigende Vaderhand die ons op het rechte spoor houdt. Natuurlijk mag men dankbaar zijn voor aards geluk, maar, zo vraagt hij zich af, is dat niet ook een teken dat God ons onze gang maar laat gaan? Zo moet de mens voortdurend opletten. Voortdurend is er de mogelijkheid gepakt en verleid te worden. Daarom moet de christen voortdurend in beweging blijven: geef de duivel geen kans. Blijf ook klein en nederig. Wees niet arrogant, verhef je niet op je voorspoed. Dat zijn allemaal de deugden van de bange, de onrustige mens ${ }^{21}$. In feite legt Cats eigenlijk ook niet goed uit wat er nu precies zo verkeerd en zondig aan de wereld is; zijn zondebesef gaat weinig diep. Wat hem steeds maar bezig houdt is dat idee: het aardse lijkt wel mooi, maar het is niet blijvend.

Het is dat vage gevoel van onrust dat hem ertoe brengt zich voortdurend af te vragen hoe hij God tevreden kan stellen. En zo is hij in Buitenleven en vooral in het ouderdomsgedicht Gedachten op slapeloose nachten steeds bezig met het probleem hoe hij met zijn aardse goederen moet omgaan ${ }^{22}$. Voortdurend pleegt hij zelfonderzoek en geeft hij adviezen als het om de arme medemens gaat. Steeds weer staan er in zijn gedichten aanwijzingen om de armen niet te vergeten. Hij wil dat men zich daar vooral niet te gemakkelijk van afmaakt. Behalve dat de armen die aan de deur komen, bedacht moeten worden, dient men ook zelfde stille armen op te zoeken. In zijn onrustige zorg om het heil kan Cats het ook niet vergeten dat in de hemel boek gehouden wordt en dat de beloning groot zal zijn: 'de minste van den hoop die brengt u voordeel aan' ${ }^{23}$. Ook de gedachte dat men door zorg voor de armen 'Godt onse schuldenaer' maakt, prijst hij als het grootste geluk aan ${ }^{24}$. De manier waarop het geformuleerd wordt, maakt niet altijd een sympathieke indruk ${ }^{25}$. Het is ook niet moeilijk zich vrolijk te maken over, of

21 Alle genoemde lessen zijn onder andere te vinden in de Sinne-en minnebeelden in Ibidem, I, 1-106: nr. 19, 36: voorspoed is gevaarlijk; nr. 40, 46: blijf in beweging; nr. 7, 8: lof van de nederigheid; nr. 13: het geluk van de armen; nr. 21b: de dood als bevrijding; nr. 30: de tijdelijkheid van aards geluk; nr. 51 : de dood neemt aards bezit af.

22 Ibidem, II, 281-348 en aan het slot (met een nieuwe telling) 3-34.

23 Buitenleven, II, 339 kol. 2.

24 Gedachten op slapeloose nachten, 15 kol. 2 passim.

25 De kapitalistische beeldspraak is opvallend. Ook Six van Chandelier verwachtte in plaats van 5 of $6 \%$ de hemel in zijn tas. Petrus Hondius, landhuisbezitter in Zeeland, bezingt in zijn Moufe-schans (1621) het geluk van het geven. Weggegeven geld 'is een rente by den Heer $\backslash \ldots . ..] \mathrm{T}$ 'is een woecker uytvercoren $\backslash$ Diemen in Gods handen lecht' (met dank aan Willemien de Vries). De beeldspraak heeft een bijbelse achtergrond met teksten als 'vergadert u schatten in den hemel' (Mattheus 6:20). 
eventueel te ergeren aan de manier waarop hij het onderwerp behandelt. In de Gedachten op slapeloose nachten maakt hij precieze berekeningen. Traditioneel, berustend op oudtestamentische aanwijzingen, bijvoorbeeld Lev. 27:30, wordt 10\% als een aanvaardbaar deel voor de armen genoemd. Cats licht dat dan als volgt toe:

Hoor noch een ander vond, gy dient uw staet te maeken

Van lasten, van gewin, ja van uw gantsche saecken,

En wat men alle jaer voor kosten dragen moet

Waerdoor het huysgesin en gy kunt zijn gevoedt.

En siet alsdan den voet van uw geheel vermogen,

En wat dan overblijft, de lasten afgetogen,

Soo neem een tiende deel van dat 'er resten sal,

Hou dat voor een die sucht in druck en ongeval ${ }^{26}$.

Zo berekend valt die $10 \%$ ook wel weer mee: het komt eigenlijk neer op $10 \%$ van wat men overhoudt na aftrek van alle kosten van levensonderhoud.

Desondanks, het is een onderwerp waarover hij steeds weer nadenkt, en sterker nog, dat voortdurend in gedachten moet zijn blijkens andere adviezen op dit punt. Heb je goed nieuws gehad, is een schip veilig geland, gaat een kind trouwen, heeft je zoon de studie succesvol afgerond of je advocaat een zaak gewonnen enzovoorts enzovoorts — Cats weet bijzonder veel gev allen op te sommen — vergeet dan ook de armen niet ${ }^{27}$. Het moge duidelijk zijn: Cats heeft het probleem van het omgaan met de eigen voorspoed gelegd naast de armoede van anderen, heel serieus genomen.

Desondanks leefde hij zeker niet in strenge ascese. In zijn Tachtig-jaren leven en huys-houding op Sorgvliet geeft hij eerst een beeld van het godsdienstig leven op het buiten met 's ochtends, 's middags en 's avonds godsdienstoefeningen. Als iemand dan veronderstelt dat hier wel een erg strenge levenswijze wordt gepropageerd, kan hij die kritiek weerleggen door op de vele aardse geneugten van jacht, spel, heerlijke maaltijden en dergelijke te wijzen ${ }^{28}$.

Veel strenger was het bestaan van de van huis uit gefortuneerde predikant Jodocus van Lodensteyn (1620-1677), mijn derde voorbeeld. Bij hem is inderdaad iets zichtbaar van het kwellende gewetensonderzoek waarover Calvijn schrijft. Steeds minder staat hij zich toe zoals valt op te maken uit de kort na zijn dood verschenen biografie en 'wat hij voor zichzelf niet nodig achtte, schonk hij echter gul aan hen die behoeftig waren: braadvlees en wijn aan de zieken, warme dekens aan de armen ${ }^{29}$.

Lodensteyn is de verliefde op Jezus. Alles wat zijn aandacht van Hem afhoudt, dient vermeden te worden. Het gaat hem in zijn poëzie zelfs niet om lessen over een deugdzaam leven, maar om die gerichtheid op God. Hij doceert niets, hij is ook geen moralist. Compromisloos wijst hij alle aardse bekommernissen af. Die consequentie

26 Gedachten op slapeloose nachten, II, 15 kol. 1.

27 Ibidem, II, 15.

28 Ibidem, II, 603-604.

29 Zoals meegedeeld in J. C. Trimp, Jodocus van Lodensteyn. Predikant en dichter (Kampen, 1987) 96. 
is begrijpelijk: wie eenmaal God verkiest, kan zich niet met het aardse bezighouden. Dan worden vragen of men nu 10 of $20 \%$ moet afstaan aan de armen, onzinnig. Het enige antwoord is in feite honderd. Wie zich in God wil verliezen, hecht aan het aardse geen belang meer.

Maar toch, ook hij, de mysticus-asceet, afkomstig uit een welgestelde familie, moest zich met het probleem van geld en goed bezighouden, en wel op verzoek van een rijke aangetrouwde nicht, weduwe van zijn neef Everhard van Lodensteyn, burgemeester van Delft. Hij doet dat in een lang gedicht, dat voor de duidelijkheid ook steeds in proza onderaan de bladzijde is samengevat: 'Opdragt van eens Christens tijdelyke Goederen aan haren Eygenaar. Alleen-sprake tot den Heere Godt', een gedicht in de vorm van een gebed dus ${ }^{30}$. De grondgedachte is dat de mens slechts rentmeester is ${ }^{31}$. Hij wordt door God voorzien van spijs en klederen. Dat zou op zichzelf genoeg zijn. Maar, zo vervolgt de dichter tot God, Uw Wijsheid heeft ons soms ook middelen in overvloed geschonken. Dat was 'enkele mildigheyd' en geen verplichting. Maar het is alles van $\mathrm{U}$ en ik draag het $\mathrm{U}$ op. Als Gij mij opdraagt het weg te geven, dan zal ik dat gaarne doen (anders dan de rijke jongeling uit het evangelie). Desondanks, op dat punt aangekomen, gaat de dichter toch het gezond verstand inschakelen. Als ik alles weggeef aan andere rijken, doen die er misschien wel iets verkeerds mee. Geef ik het aan de armen (en geven die ook het kapitaal weg) dan zouden de latere armen niets meer hebben. Dat kan toch de bedoeling niet zijn. En de conclusie is dan ook dat het kapitaal bewaard moet blijven.

Verder nadenkend komt hij tot het volgende, waarbij hij zich weer tot God richt: Gij laat de ongelijkheid toe in uw raad, maar 'ons hebt Gy aan 't Gebod van gelijkheyd gebonden, en komt Uw gebrek lydende kinderen met de liefdewet weder te hulpe ${ }^{132}$. Dit sluit aan op bijvoorbeeld het Zeeuwse piëtisme van Teellinck dat een sociale trek heeft in zijn kritiek op de overdaad van de rijken tegenover de nood der armen die ze niet willen lenigen. Geloof wordt dan minder opgevat als 'een stellig weten' en 'een vast vertrouwen ' zoals de Heidelbergsche Catechismus het in Zondag 7 uitdrukt, maar vooral als liefdegemeenschap met God en Christus. Dan klinkt de taal van de mystiek die ook in Lodensteyns lyriek zo vaak te beluisteren valt ${ }^{33}$.

Zuinigheid en mildheid behoren dus samen te gaan: zuinigheid om de hoofdsom in stand te houden; mildheid om de mede-lidmaten van het ene lichaam te helpen. Dat laatste mag desnoods, als het nodig is, ook ten koste van de hoofdsom. Het geld echter zomaar wegdoen, zou betekenen dat de rijke afzag van de speciale opdracht die God hem blijkbaar heeft gegeven.

Maar zich verlustigen in goud, edelstenen en andere luxe is dwaasheid. En hier is Lodensteyn heel precies: het is ook niet voldoende je alleen maar te onthouden van

30 J. van Lodensteins Uitspanningen [...], II (4de dr.; Rotterdam, 1725) 31-69.

31 Calvijn werkt dezelfde gedachte kort uit in Institutie III, x, 4.

32 J. van Lodensteins Uitspanningen, 43.

$33 \mathrm{Vgl}$. P. J. Meertens, Letterkundig leven in Zeeland in de zestiende en de eerste helft der zeventiende eeuw (Amsterdam, 1943) 175-178. 
onrecht, list, woeker, oneerlijke prijzen, en zelfs is het niet toereikend de armen iets te geven en alles te doen wat een eerlijk man doet. Want als er dan toch die stille lust, en Rust op den Rijkdom is, blijft men de verkeerde houding innemen ${ }^{34}$.

Zo probeert hij, op een principiëlere manier dan Cats, de rijken aanwijzingen te geven hoe met hun aardse goed te handelen: bezit het als niet-bezittend. Daarbij valt dan op hoe letterlijk het rentmeesterschap wordt beschouwd als zorg voor de instandhouding van het kapitaal. Ook dat heeft Lodensteyn bij testamentaire voorziening in de praktijk gebracht. Weliswaar zijn er belangrijke legaten voor een groot aantal instellingen en personen, maar het familiekapitaal blijft in stand ${ }^{35}$.

Moeten we bij deze veelgelezen en gezongen auteur dan de ware gereformeerde identiteit zoeken? Is zijn voorbeeld van ascese in het dagelijks leven in de gereformeerde kerken algemeen gevolgd? We weten wel beter. Een recente reeks artikelen in Trouw laat zien dat ook in de meest bevindelijke kringen in het huidige Nederland het omgaan met de Mammon een problematische aangelegenheid is ${ }^{36}$. Zo de televisie ontbreekt, staat toch niet zelden een Mercedes voor de deur.

Six van Chandelier schoof het probleem wat terzijde, als christen in de vrijheid genietend van het leven, maar daarbij de armen toch wel wat uit het oog verliezend. Cats probeerde het zuchtend en rekenend op te lossen, zoekend naar een weg die het hem zou toestaan het leven dankbaar te genieten en toch met God in het reine te zijn. Lodensteyn stelde de zaak principieel en zag de christen uitsluitend als rentmeester maar creëerde geen ruimte meer voor de aardse geneugten. Een dichterlijke oplossing voor het probleem bestaat niet, zoals ik dat hierboven ook al voorspeld had, hoogstens reikten deze drie auteurs modellen aan vooreen leven in welvaart die ook nu nog steeds vertoond worden maar waarvan ik het toch niet graag zou volhouden dat ze een exclusief trekje van de Nederlandse identiteit uitmaken. 